\title{
Error Analysis on Prospective Teacher in Solving the Problem of Critical Thinking Mathematics with Apos Theory
}

\author{
$1^{\text {st,a,b }}$ Ardi Dwi Susandi \\ ${ }^{a}$ Universitas Nahdlatul Ulama (UNU) \\ Cirebon \\ bUniversitas Negeri Malang \\ Malang, Indonesia \\ Corresponding author: \\ ardi.dwi.1603119@students.um.ac.id \\ $4^{\text {th }}$ Susiswo \\ Universitas Negeri Malang \\ Malang, Indonesia \\ susiswo.fmipaum.ac.id
}

\author{
$2^{\text {nd }}$ Cholis Sa'dijah \\ Universitas Negeri Malang \\ Malang, Indonesia \\ cholis.sadijah.fmipa@um.ac.id
}

\author{
$3^{\text {rd }}$ Abdur Rahman As'ari \\ Universitas Negeri Malang \\ Malang, Indonesia \\ abdur.rahman.fmipa@um.ac.id
}

\begin{abstract}
Abstrak: Mathematical critical thinking is an essential ability for prospective teachers. The prospective teachers must be able to use the ability to think critically well so that students who are taught can also have good mathematical critical thinking skills. However, sometimes prospective teachers have a mistake in solving the problem of critical mathematical thinking skills. The present paper aims to analyze the mistakes of prospective teachers in solving the problem of critical mathematical thinking skills. The type of research method is descriptive with the qualitative approach. The subject in this research is one student of semester VI. The methods used in this research include test method amounting to one essay question, interview method, and triangulation method. The findings show that the prospective teacher on the focus indicator can be completed well whereas the indicators of reason, inference, situation, clarity, and overview, the teacher cannot solve well. Causes of the teacher error based on APOS theory are (1) error in distinguishing between commutative and addition characteristic of multiplication on matrix, (2) error in multiplication operation on the matrix, (3) error inequality of two matrices, and (4) error in the concept of inverse equation matrix.
\end{abstract}

Keywords- Error Analysis, Critical Thinking Ability of mathematics, APOS Theory.

\section{INTRODUCTION}

Mathematical critical thinking ability is one of the crucial components for prospective teachers. A prospective teacher should be able to use the critical thinking skills of mathematics well so that students who are taught can also have good mathematical thinking skills. In addition, according to Howie, critical thinking is construed as the highest intellectual activity in human interaction and allows people to engage in meaningful decision-making processes [1]. However, sometimes prospective teachers have errors in solving the problem of critical mathematical thinking skills. The error was due to the poor development of earlier mathematical concepts. The mistake made it difficult for pre-service teachers to detect misconceptions that occur in the students, so prospective teachers are wrong in providing strategies to improve the misconception. Kilic's finding supports this discourse, that prospective teachers have difficulty in identifying the source of student misconceptions so that mistakes in producing an effective way to eliminate these misconceptions [2].

There are many opinions from experts on indicators of critical thinking ability. One of the indicators of critical thinking ability according to Ennis is focus, reason, inference, situation, clarity, and overview [3]. The focus is to determine what questions or issues are available to decide on the issue. Situation (i.e., situations) that apply the concept of prior knowledge to solve problems in other situations. Inference (conclusion) is to estimate the conclusion of the reasons that have been put forward correctly. Reason (reason) is to provide reasons for answers that support or against decisions made based on relevant situations and facts. Clarity (clarity) is to give an example of a similar problem or problem on the conclusion presented. The overview is to re-examine and examine the truth thoroughly the decisions taken.

Some prospective teachers sometimes forget these essential mathematical critical thinking skills. The inability of prospective teachers to meet the indicator of critical thinking ability of mathematics is presumed because of the mental process of prospective teachers in understanding the concepts that exist in the mathematics is still lacking so when working on the problem of having an error. Therefore, it must be checked the mental process of prospective teachers in working on the problem of critical mathematical thinking skills provided. The way that is used to check the process of prospective teachers is using the theory of APOS. According to Arnon et al., the theory of APOS generally consists of four stages of action, processes, objects, and schemes [4]. The action is the ability to understand concepts by using external stimuli. A process is the ability to think of the same actions based on specific inputs and outputs without having to do explicitly. An object is the ability to realize a process as a whole, realizing, and transforming action based on its entirety and can build transformations explicitly. A scheme is the ability to build relationships of actions, processes, objects, and other schemes to solve problems. By using the stages in APOS 
theory, it is expected to know the mistakes that occur in prospective teachers when doing math problems.

Much research has been done on critical thinking skills. Research conducted by Choy \& Cheah, concludes that teachers do not seem to understand the requirements needed to foster critical thinking among students [5]. Although teachers feel that they encourage critical thinking in the classroom, they focus solely on understanding the subject matter. Research conducted by Aktas \& Unlu, concluded that the critical thinking skills of the basic mathematics preservice teacher are at the middle level but not high enough level [6]. Research conducted by Alwadai, concluded that prospective teachers find the biggest obstacle in improving students' critical thinking skills is the ability of students themselves[7]. The research by Applebaum \& Mark concluded that prospective teachers found it difficult to develop critical thinking skills because of difficulties in analyzing the probability of mistakes and overcoming the students' mental incompatibility when faced with opposing answers to geometry [8]. Research conducted by Moeti, et al. concluded that the trainees had a lower description of the problem of critical thinking [9]. However, the students were well aware of the factors that influenced the inability to think critically during the training. This finding clearly shows that most students do not apply critical thinking during the training.

Based on research that has been done about the ability of critical thinking proved that both students, prospective teachers, as well as teachers generate critical thinking skills that have not been maximized. However, from the results of existing research, no one has examined about why the critical thinking skills of mathematics teacher candidates have not been maximal or even still low. Therefore, the goal to be achieved in this research is to analyze what errors occur in the candidate math teacher in solving the problem of critical thinking skills mathematics by using the theory of APOS.

\section{METHOD RESEARCH}

The type of research used is descriptive research with the qualitative approach. In this research, there is one semester VI student selected as the research subject. The reason for taking this subject is because the sixth-semester students already have experience in teaching materials to students. In this study, the methods used include test methods, interview methods, and triangulation methods.

The primary instrument in this study is the researcher himself and equipped with the test and interview instruments. The tests in this study used the critical, critical thinking skills test based on focus, Reason, Inference, Situation, Clarity, and Overview indicators consisting of one essay question. Prospective teachers were working on problems that have been made by researchers. Then the test results are confirmed through interviews with selected subjects. Interviews used in this study are semi-structured interviews because the interview guidelines have been prepared first based on the answers of prospective teachers, but the question can be developed following the circumstances and characteristics of research subjects. This interview is flexible and allows researchers to follow subject thinking without switching from the initial goal of the interview is to know the mistakes of prospective teachers in working out the problem of critical mathematical thinking skills using the APOS theory. Then the next step, using data triangulation method that is comparing the test results from mathematics with the results of interviewing prospective teachers.

The following is a test of critical mathematical thinking skills used in this study: While following a daily mathematical test, Budi gets a question from his teacher to investigate the following statement:

"If $A, B$, and $C$ are $2 \times 2$ matrices, then $A(B+C)=A B+$ $C A$. "Then Budi replies that the statement is true because if

$$
A=\left(\begin{array}{ll}
1 & 0 \\
0 & 1
\end{array}\right), B=\left(\begin{array}{cc}
-1 & 1 \\
0 & 0
\end{array}\right), C=\left(\begin{array}{ll}
0 & 1 \\
0 & 1
\end{array}\right)
$$$$
\text { then } A(B+C)=A B+C A \text {. }
$$

What do you think? Do you agree with Budi's answer? Give the reason!

\section{Result of Research \\ III. RESULT AND DISCUSSION}

Answers to pre-service teachers: Based on the problem of critical mathematical thinking skills that have been done by prospective teachers of mathematics, then the following answers from prospective teachers of mathematics: In the Focus indicator, the mathematics preservice teacher is able to write down the known and asked questions on the matter done and can argue which is different from the given problem; In the Situation indicator, the pre-service mathematics teacher does not check the answers already in the question; In the Inference indicator, the mathematics teacher prospective consider the answers that have been available in the question is the correct answer and no other answers; In the Reason indicator, the mathematics teacher prospective only proves the answer to the question and does not get another idea about the answer itself; In the Clarity indicator, the pre-service mathematics teacher concludes that the statement in the given question is true; and In the Overview indicator, the pre-service mathematics teacherprospective concludes that the statement in question is the correct answer and applies to all types of matrices.

To obtain information from prospective mathematics teachers about the problems that have been done, then needed an interview to the subject. The purpose of holding an interview is to confirm the answer that has been done. Then to identify the mistakes of pre-service mathematics teacherprospective in the matter of mathematical critical thinking skills given by using APOS theory. Here are the results of interviews on prospective math teachers:

Interviews with prospective teachers: Based on the results of interviews with prospective teachers of mathematics obtained information as follows: when the prospective math teacher is asked where that is known and asked it is obtained, then the mathematics teacher prospective responds that it can write down the known and asked questions obtained from reading the given matter carefully; When the prospective math teacher is asked why not check the answer in the question, then the mathematics teacher prospective replied not to be checked because the answer is correct; when the prospective math teacher is told 
to check the answers that already exist in the matter, then the prospective math teacher is confused about how to check the answer; when the prospective math teacher is asked about the properties of the matrix, the mathematics teacher prospective answers forgot to open the book again; when the prospective math teacher is asked about operations on the matrix, the mathematics teacher prospective can only explain the addition and subtraction operations of the matrix only, whereas the multiplication operation on the matrix cannot be operated. When the preservice math teacher is asked how two matrices are said to be the same and give an example, the mathematics teacher prospective only answers two matrices are said to be the same when the numbers on both matrices are the same and can not provide an example. Also when the pre-service mathematics teacher is asked what the formula of the inverse matrix is, then the mathematics teacher prospective answers the forgot because the material is old.

\section{Discussion of Research}

From the results of answers and interviews to preservice teachers of mathematics, the following analysis of the discussion steps of workmanship answers based on indicators of critical thinking and theories of APOS: the analysis for the focus indicator of the pre-service teachers are able to write down the known and asked questions in order to make a decision on the matter. This discourse is aligned with the focus indicator that is able to determine what questions or issues are available to decide on the issue. This also proves that the focus indicator of pre-service mathematics teacher is not faulty, so it is not necessary to check using APOS theory. Not the occurrence of errors in the indicator of this focus because the pre-service mathematics teacher is used when working on the problem of writing the known and asked first before proceeding to the next stage.

Analysis of Situation indicators, prospective teachers, do not check the answers that already exist in the matter because the answer is correct. However, when told to check the answer, the pre-service teacher is having trouble. This issue is not following the situation indicator (i.e., situation) that is applying the concept of knowledge possessed previously to solve the problem in other situations. Analysis for situation indicator based on APOS theory, prospective teachers, cannot operate multiplication on matrix. This evident from the results of interviews, prospective teachers when told to prove the answer which can only operate the summation matrix. In the step of matrix multiplication operation, the prospective teacher is having difficulties and cannot continue the work result. It means that prospective teachers cannot use the concept of multiplication on the matrix well. Based on the analysis of the problem, then at the stage of action or action in the analysis of APOS that prospective teachers have limited understanding of the concept of multiplication operations in two matrices measuring $2 \times 2$. At the high school level, prospective teachers do not study the concept of operation of two matrix multiplication thoroughly. Prospective teachers memorize the material given by the teacher so that the concept is not appropriately stored in the memory of his brain. The mistakes of prospective teachers on the concept of multiplication operation of two matrices based on APOS analysis mostly occur in prior learning which is more concerned with rote and procedure without having to understand the concepts studied. This is in line with the results of Siyepu's research, which states that students' mistakes on trigonometric derivative functions based on APOS theory analysis are mostly derived from previous mathematical learning and more than generalizations of certain mathematical rules [10]. Rote learning routines or procedures dominate the student's previous learning without students understanding them.

Analysis of Inference indicators, prospective teachers, conclude that there is no different answer other than the answer in the question so agree with the statement in question. When given another matrix and told to do the prospective teacher is also experiencing difficulties so it cannot give other conclusions. This is not following the Inference indicator which is to estimate other conclusions from the reasons already stated correctly. Analysis of Inference indicators based on APOS theory, prospective teachers, cannot do the problem when given other problems. Based on the interview, the prospective teacher cannot distinguish the lowercase letters and capital letters on the matrix. In addition, prospective teachers are unable to distinguish between common matrix symbols and matrix determinant symbols. Then on the process of working on prospective teachers have difficulty so cannot solve the problem well. The findings indicate that prospective teachers are not successful at the process and object stage in APOS theory because the prospective teacher cannot perform the problem-solving steps well and cannot distinguish mathematical symbols so can not conduct inference well. Therefore, if the prospective teacher wants to succeed in the process and object stage, the prospective teacher does not just use symbols in mathematics but also must make conclusions along with the reasons. This is reinforced by the opinion of Caraher et al., that students not only use notations or symbols but also must be able to provide scientific reasons, make conclusions, and generalizations in the student's own way [11].

The analysis for a reason indicator, the prospective teacher, only gives the reason for the answer to the question and cannot give another reason for the answer because the previous indicator is not fulfilled. However, the prospective teacher is wrong in giving the reason for the answer in the matter. This means that it is incompatible with the reason indicator that is giving reasons for the answer that supports or against the decision made based on the relevant situation and facts. The analysis for a reason indicator based on APOS theory, the prospective teacher is wrong in distinguishing between the commutative nature of addition and multiplication on the matrix. Based on the interview, the prospective teacher assumes that the commutative nature of addition and multiplication have the same rules that assume that $A+C=C+A$ result is equal to $A C=$ $C A$. Furthermore, when asked the matrix inverse how, the prospective teacher can only mention the formula. When asked to solve the question of the inverse matrix, the prospective teacher just wrote the formula alone and can not explain the formula so it can not solve the problem until the end. Based on these findings, the prospective teacher did not succeed at the scheme stage of the APOS theory because the prospective teacher was able to name the 
formula, but could not give a good reason regarding the expressed formula so that the prospective teacher could not relate between the concepts used in the matter in a scheme. Therefore as a prospective teacher should be able to make a pedagogical decision well to avoid errors in a scheme. This is reinforced by Prachagool et al. opinion, making pedagogical decisions crucial for professional teachers because it involves confidence, success, and showing the actions of the teacher in the classroom [12].

The analysis for the Clarity indicator, the prospective teacher, assumes that the nature of the matrix in question can be generally applicable so that the statement in the matter is valid and does not need to provide an example. It is inconsistent with the Clarity indicator (clarity) that provides an example of a similar problem or problem to the conclusion presented. The analysis for indicators of clarity based on APOS theory, prospective teachers, incorrectly equals two matrices. Based on the interview, the prospective teacher assumes that the distributive nature of $A(B+C)=A B+C A$ is the similarity of two matrices so that the result is the same. In fact, however, the result of the distributive nature of the result is equal to certain conditions and therefore does not generally apply to every matrix. This is due to the teacher's incompetence to the commutative nature of the matrix multiplication to have an impact on the error in determining the similarity of the two matrices. It can also be concluded that prospective teachers did not succeed at the scheme stage of the APOS theory because prospective teachers could not relate to the concepts used in the matter in a scheme. This happens because prospective teachers do not have a good understanding of mathematical concepts. This is in line with the results of research Brijlall \& Ndlovu that students can answer derivative questions, but students do not have a good understanding of mathematical concepts to make conceptual mistakes [13].

Analysis of overview indicators, prospective teachers conclude that the answers in the question generally apply so that the statement is true. However, checks on the answers obtained by prospective teachers are wrong. It is not following the Overview indicator is to re-examine and examine the truth thoroughly the decisions taken. Analysis of indicators Overview based on APOS theory; prospective teachers cannot conclude the problem well so that there is a mistake in the final answer. This issue occurs because of the influence of the previous stage of error in the process of making the problem so that in concluding the final result also experienced an error. It can be concluded that prospective teachers did not succeed at the stage of action, process, object, and schema of the APOS theory. This problem happens because the prospective teacher cannot do the problem well so that the error in concluding the final result.

Based on these explanations, the general response of prospective teachers in solving the problem of critical thinking skills of mathematics is at the level of action or action on the theory of APOS. This discourse as reflected in the problem that has been given, the prospective teacher is unable to complete the test questions and can not mention the process through which to answer the question. Prospective teachers can not draft into a process. The scheme of all concepts in the matrix is not assimilated into the cognitive structure of the prospective teacher. It is inconvenient that a prospective teacher fails to coordinate a scheme with other existing schemes. The study revealed that some aspects of APOS theory are not fully operational, because prospective teachers are not successful in recalling the concepts used in solving the given problem. Prospective teachers can not manipulate the concept properly so they can not follow the instructions given in applying the rules that have been memorized. One way to improve the four components of APOS theory is to use an appropriate learning model. Mudrikah reinforces this, the problembased learning model presented through the eight learning steps has been able to improve the students' mental actions because they can be used to stimulate reflective abstraction in students thus building knowledge in Action-ProcessObject-Schema theory [14]. Further according to Akyuzet et al., metacognitive guidance in the learning environment can be a useful tool in developing critical thinking in prospective teachers [15].

Identification of errors based on APOS theory by prospective teachers in working on the problem of critical mathematical thinking skills to help prospective teachers to know the weaknesses that exist in itself. The weaknesses occur because teachers have a narrow view of critical math skills. This is reinforced by the opinion of Stapleton, that the teachers have some conception of the term on critical thinking that tends to be narrow so that there is a mistake in looking at the ability to think critically [16]. From the mistakes that have been found, the prospective teacher must improve the ability to think critically in various ways that can impact on the development of critical thinking skills of students who are taught mathematics. This assertation is supported by the opinion of Peter, several ways that can improve the ability to think critically about math both middle school and post-secondary level, among others [17]. For instances: using active learning strategies involving students in the learning process the focus of learning on the learning process is not on the results, and use assessment techniques that give students intellectual challenges rather than self-assessments of memory or rote. Furthermore, according to Tiruneh et al., the effectiveness of critical thinking teaching is influenced by the conditions in the learning environment consisting of teaching variables (learning strategies and critical thinking teaching approaches), and the variables related to students (year level and academic achievement of students) [18]. Therefore, with the development of students' critical thinking skills in mathematics, students will be able to have a mental structure based on good APOS theory. This is in line with Aksu \& Koruklu's research that students' increased mathematical critical thinking skills will allow students to see everything from various aspects and will provide opportunities to find formulas and rules [19]. Furthermore, according to Huang et al., A teachers who emphasize reasoning, logic, and validity give students access to mathematics as an effective way to practice critical thinking thus allowing students to become confident critical thinkers [20].

\section{CONCLUSION}

Based on the data analysis and discussion of the research, it can be concluded that the pre-service 
mathematics teacher in the focus indicator can solve the problem well while in the indicator Reason, Inference, Situation, Clarity, and Overview cannot solve the problem well. The causes of mathematical teacher prospective error based on APOS theory are: (1) Error in distinguishing between commutative and addition characteristic of multiplication on matrix, (2) error in multiplication operation on matrix, (3) error inequality of two matrices, and (4) error in the concept of inverse equation matrix.

\section{ACKNOWLEDGMENTS}

The research on which this study was based was supported by international scholarship funding from the LPDP (Institute of Education Fund Management) of the Indonesian republic.

\section{REFERENCES}

[1] Howie, D. R., Teaching students thinking skills and strategies [electronic resource]: A framework for cognitive education in inclusive settings/Dorothy Howie. London: Jessica Kingsley. (2011).

[2] Kilic, H., The Nature of Preservice Mathematics Teachers Knowledge of Students. Procedia-Social and Behavioral Sciences, 9, 1096-1100. (2010)

[3] Ennis, R. H., Critical Thinking. New Jersey. Prentice-Hall Inc. (1996).

[4] Arnon, I, Cottrill, J, Dubinsky, E, Oktaç, A, Fuentes, SR, Trigueros, M, \& Weller, K., APOS Theory: a framework for research and curriculum development in mathematics education. London: Springer. (2014)

[5] Choy, S.C., Cheah, P.K. "Teacher Perceptions Of Critical Thinking Among Students And Its Influence On Higher Education." International Journal of Teaching and Learning in Higher Education, Volume 20, Number 2, 198-206. (2009).

[6] Aktas, G. \& Unlu, M. "Critical Thinking Skills of Teacher Candidates of Elementary Mathematics." Procedia Social and Behavioral Sciences, Vol. 93, Pp. 831-835. (2013)

[7] Alwadai, M.A., "Islamic Teachers' Perceptions of Improving Critical Thinking Skills in Saudi Arabian Elementary Schools." Journal of Education and Learning; Vol. 3, No. 4, Pp. 37-48. (2014).

[8] Applebaum \& Mark. "Activating pre-service mathematics teachers' critical thinking." European Journal of Science and Mathematics Education, Vol. 3, No. 1, 77-89. (2015)

[9] Moeti, B., Mgawi, R.K., \& Moalosi, W.T.S., "Critical Thinking among Post-Graduate Diploma in Education Students in Higher Education: Reality or Fuss?" Journal of Education and Learning Vol. 6, No. 2; Pp. 13-24. (2016).

[10] Siyepu, S.W. "Analysis of errors in derivatives of trigonometric functions." International Journal of STEM Education, Vol. 2, No. 16, Pp. 1-16. (2015).

[11] Caraher DW, Martinez MV\&Schielmann AD., Early algebra and mathematical generalization. ZDM Math. Educ. 40:3-22. (2008).

[12] Prachagool., et al. "Pedagogical Decision Making through the Lens of Teacher Preparation Program." Journal for the Education of Gifted Young Scientists, 4(1) 41-52. (2016)

[13] Brijlall, D., \& Ndlovu, Z. "High School Learners Mental Construkction during Soling Optimisation Problem in Calculus: a
South African Case Study." South African Journal of Education, 33(2). (2013).

[14] Mudrikah, A. "Problem-based learning associated by action-processobject-schema (APOS) theory to enhance students' high order mathematical thinking ability." International Journal of Research in Education and Science (IJRES), 2(1), 125- 135. (2016).

[15] Akyuz, H.I., Yetik, S.S., \&Keser, H. "Effects of Metacognitive Guidance on Critical Thinking Disposition." Pegem Eğitimve Öğretim Dergisi, Vol. 5, No. 2, Pp. 133-148. (2015).

[16] Stapleton, P. "A Survey of Attitudes Towards Critical Thinking among Hongkong Secondary School Teachers: Implications for Policy Change.” Thinking Skills and Creativity, Vol. 6, Pp. 14-23. (2011).

[17] Peter, E.E., "Critical thinking: Essence for teaching mathematics and mathematics problem-solving skills." African Journal of Mathematics and Computer Science Research Vol. 5(3), pp. 39-43. (2012).

[18] Tiruneh, D.T., Verburgh, A., \& Elen, J., "Effectiveness of Critical Thinking Instruction in Higher Education: A Systematic Review of Intervention Studies." Higher Education Studies; Vol. 4, No. 1, Pp. 1-17. (2014).

[19] Aksu, G., \& Koruklu, N. "Determination of the Effects of Vocational High School Students' Logical and Critical Thinking Skills on Mathematics Success." Eurasian Journal of Educational Research, Issue 59, Pp. 181-206. (2015).

[20] Huang, H.F., et al., "Mathematical Teaching Strategies: Pathways to Critical Thinking and Metacognition." International Journal of Research in Education and Science (IJRES), Vol. 2, No. 1, Pp. 190200. (2016). 